\title{
Failure to demonstrate an advantage in combining sulphamethoxazole with trimethoprim in an experimental model of urinary infection
}

\author{
J. D. ANDERSON, ${ }^{1}$ R. W. LACEY, E. L. LEWIS, AND M. A. SELLIN \\ From the Department of Bacteriology, The Medical School, Bristol
}

SYNOPSIS Co-trimoxazole was found to have a predominantly bacteriostatic effect upon 28 urinary isolates of Enterobacteriaceae in nutrient broth and was never bactericidal in artificially infected urine. The components of co-trimoxazole were tested individually and trimethoprim was found to be at least as effective as co-trimoxazole in nutrient broth and in urine. Trimethoprim alone produced some bactericidal effect in urine but this was antagonized by sulphamethoxazole.

Laboratory tests for evaluating these drugs may give a misleading impression of their activity in vivo. Further clinical comparisons should therefore be made between trimethoprim and cotrimoxazole to determine when trimethoprim should be used in preference to the combination.

Despite the absence of a full evaluation of trimethoprim itself, a combination with sulphamethoxazole (co-trimoxazole) was introduced into general clinical use in 1968 and has been widely used since. A Swiss clinical trial showed that there was very little overall difference between trimethoprim and the combination in the treatment of urinary tract infections (Hoigné, Müller, and Schneider, 1969). A later English investigation showed that trimethoprim was as effective as co-trimoxazole in domiciliary patients but the mixture appeared to be superior in hospital patients (Brumfitt and Pursell, 1972). The latter results may possibly be less conclusive than they appear because hospital infection may be due to epidemics of a few organisms or to transferable antibiotic resistance within a bacterial population. Co-trimoxazole has been shown to be more effective than its components in chronic urinary tract infections caused by Enterobacteriaceae (Gleckman, 1973). However, this last study was not representative of commonly occurring urinary infections since it involved a population with a mean age of 59 years consisting of about $48 \%$ males.

Some of the properties initially attributed to cotrimoxazole in vitro have been found to be unpredictable. It now appears that the combination is

'Present address: The Group Pathology Laboratories, The County Hospital, York, YO3 7PG.

Received for publication 8 May 1974. more often bacteriostatic rather than cidal in vitro (Küchler and Koch, 1973; Lacey, Anderson, Lewis, and Gillespie, 1973; Lewis, Anderson, and Lacey, 1974) and that any cidal activity may be due to the trimethoprim component alone (Lewis et al, 1974).

In order to obtain a more realistic assessment of the activity of these drugs in vitro we have studied the antibacterial activity of co-trimoxazole and its components in artificial mixtures in urine and in urine from volunteers some of whom had taken therapeutic doses of these agents. The results indicate that trimethoprim alone may be expected to be as effective as co-trimoxazole in the treatment of urinary infections.

\section{Methods}

\section{PATIENTS AND ORGANISMS}

Twenty-eight isolates of Enterobacteriaceae were obtained from 12 outpatients and 16 inpatients who had significant urinary tract infections. Specimens were obtained from five hospitals within a 20 mile radius of Bristol over a period of several weeks in order to minimize the possibility of collecting the same organism or the same plasmid-mediated resistance determinant from different patients. The organisms were identified (Cowan and Steele, 1965) as Escherichia coli, 26; atypical E. coli, one; Proteus morganii, one. Nine of these organisms were resistant to sulphamethoxazole alone and one to both trimethoprim and sulphamethoxazole. 
DETERMINATION OF MINIMUM INHIBITORY CONCENTRATIONS (MICS) IN BROTH

Sulphamethoxazole and trimethoprim were incorporated in doubling dilutions, singly or in combination (usually in a ratio of $20: 1 \mathrm{w} / \mathrm{w}$ ) into plates containing Oxoid diagnostic sensitivity test agar with the addition of $5 \%(\mathrm{v} / \mathrm{v})$ lysed horse blood. Further details have already been described (Lewis et al, 1974). Resistance to sulphonamides was defined as an MIC of $>200 \mu \mathrm{g}$ of sulphamethoxazole per $\mathrm{ml}$; resistance to trimethoprim as an $\mathrm{MIC}$ of $>1.6$ $\mu \mathrm{g}$ per $\mathrm{ml}$.

DETERMINATION OF MINIMUM BACTERICIDAL CONCENTRATIONS IN BROTH

As already described, using broth containing $5 \%$ (v/v) lysed horse blood (Lewis et al, 1974). A bactericidal effect has been defined as a reduction of tenfold or more in viable count within a stated time.

ANTIMICROBIAL AGENTS

Sulphamethoxazole and trimethoprim lactate were obtained as powders for incorporation into various media from Burroughs Wellcome Ltd. Volunteers were given the following formulations: sulphamethoxazole tablets, $500 \mathrm{mg}$ (Gantanol tablets, Roche Products); trimethoprim tablets, $80 \mathrm{mg}$ (Burroughs Wellcome Ltd.); co-trimoxazole tablets, ie, sulphamethoxazole $400 \mathrm{mg}$ with trimethoprim, $80 \mathrm{mg}$ (Septrin tablets, Burroughs Wellcome Ltd).

PREPARATION OF URINE FOR USE AS A

BACTERIAL MEDIUM

Urine was collected on the third day of a course of treatment with each antimicrobial agent. Healthy volunteers were given either co-trimoxazole, two tablets twice daily; or trimethoprim, $80 \mathrm{mg}$, two tablets twice daily, or sulphamethoxazole, $500 \mathrm{mg}$, two tablets twice daily. The urine was cooled to $4^{\circ}$ after voiding, sterilized by filtration, and then pooled. The possibility that filtration altered the antibacterial properties of the urine was excluded. Some specimens of urine were stored at $-20^{\circ}$ before use; freezing led to the precipitation of solid matter but did not affect the antimicrobial properties.

For certain experiments 24-hr collections of midstream urine from healthy individuals were treated as described above. Sulphamethoxazole, or trimethoprim, or the combination (ratio 20:1 w/w) were then added to the urine as already described (Lewis et al, 1974).

BEHAVIOUR OF ORGANISMS IN URINE

Overnight broth cultures $(10 \mathrm{ml})$ of organisms were washed twice by centrifugation and then resuspended in saline to remove substances accumulating in the broth which might inhibit trimethoprim or sulphonamides. Prewarmed urine was inoculated with between $10^{5}$ and $10^{6}$ organisms per $\mathrm{ml}$ and immediately sampled for viable bacteria (Miles, Misra, and Irwin, 1938) on MacConkey agar plates. The viable count was determined again after incubation of the flasks on a shaker at $37^{\circ}$ for two, four, and six hours.

\section{Results}

ANTIBACTERIAL EFFECT OF CO-TRIMOXAZOLE AND ITS COMPONENTS IN NUTRIENT BROTH MEDIUM

Co-trimoxazole and its components when tested individually were usually bacteriostatic against most organisms in nutrient broth containing $5 \%(\mathrm{v} / \mathrm{v})$ lysed horse blood (table I).

\begin{tabular}{llll}
\hline $\begin{array}{l}\text { Antibacterial Agent Added } \\
\text { (32 } \times \text { MIC in each case) }\end{array}$ & $\begin{array}{l}\text { No. of Cultures Killed at Time } \\
\text { Shown }\end{array}$ \\
\cline { 2 - 3 } & Two Hr & Four Hr & Six Hr \\
& & & \\
\hline Sulphamethoxazole & 0 & 0 & 0 \\
Trimethoprim & 0 & 2 & 5 \\
Co-trimoxazole & 0 & 1 & 3 \\
\hline
\end{tabular}

Table I Effect of added antibacterial agents upon 28 urinary isolates of Enterobacteriaceae in nutrient broth containing $5 \%(v / v)$ lysed horse blood

${ }^{1}$ Cidal effect defined in methods section.

ANTIBACTERIAL PROPERTIES OF CO-TRIMOXAZOLE AND ITS SEPARATE COMPONENTS IN URINE

In order to obtain optimal activity of sulphonamides and trimethoprim in vitro certain precautions have to be taken to neutralize naturally occurring antagonists in the media. The nature and extent of such antagonists in the body are unknown so that any attempt to correlate antibacterial activity in vitro with projected activity in clinical practice is at best only approximate. The activity of these agents was therefore determined in urine where it is found that sulphamethoxazole, or trimethoprim, or a 20:1 (w/w) was seldom bactericidal (table II). Trimethoprim was significantly superior (Student paired $t$ test) to co-trimoxazole at two hr $(\mathrm{P}=0.02)$ but the two agents were not significantly different at four hr $(\mathrm{P}=0.45)$ or six hr $(\mathrm{P}=0.55)$. Co-trimoxazole was superior to sulphamethoxazole at six $\mathrm{hr}(\mathrm{P}=$ $0.05)$ but not at two hr $(\mathrm{P}=0.65)$ or four $\mathrm{hr}(\mathrm{P}=$ 0.75). Sulphamethoxazole antagonized the cidal effect of trimethoprim on the occasions when this 


\begin{tabular}{|c|c|c|c|}
\hline \multirow[t]{2}{*}{ Test System } & \multicolumn{3}{|c|}{ Time of Incubation } \\
\hline & Two $\mathrm{Hr}$ & Four $\mathrm{Hr}$ & Six $\mathrm{Hr}$ \\
\hline Urine control & $\begin{array}{c}0 \\
2 \cdot 8 \\
(0 \cdot 8 \rightarrow 6 \cdot 3)\end{array}$ & $\begin{array}{c}0 \\
100 \\
(1 \cdot 3 \rightarrow 340)\end{array}$ & $\begin{array}{c}0 \\
1010 \\
(13 \rightarrow 4700)\end{array}$ \\
\hline Urine containing $1 \mathrm{mg}$ per $\mathrm{ml}$ sulphamethoxazole & $\begin{array}{c}0 \\
0.97 \\
(0.3 \rightarrow 3.4)\end{array}$ & $\begin{array}{c}0 \\
1 \cdot 0 \\
(0 \cdot 2 \rightarrow 3 \cdot 1)\end{array}$ & $\begin{array}{c}0 \\
1 \cdot 8 \\
(0.09 \rightarrow 7)\end{array}$ \\
\hline Urine containing $50 \mu \mathrm{m}$ per $\mathrm{ml}$ trimethoprim & $\begin{array}{c}0 \\
0.84 \\
(0 \cdot 2-2 \cdot 5)\end{array}$ & $\begin{array}{c}5 \\
0.34 \\
(0.02-\rightarrow 8 \cdot 0)\end{array}$ & $\begin{array}{c}8 \\
1 \cdot 4 \\
(0.008 \rightarrow 20)\end{array}$ \\
\hline $\begin{array}{l}\text { Urine containing } 1 \mathrm{mg} \text { per } \mathrm{ml} \text { sulphamethoxazole and } 50 \mu \mathrm{g} \text { per } \mathrm{ml} \\
\text { trimethoprim }\end{array}$ & $\begin{array}{c}0 \\
1 \cdot 0 \\
(0 \cdot 5 \rightarrow 2 \cdot 7)\end{array}$ & $\begin{array}{c}0 \\
1 \cdot 1 \\
(0 \cdot 5 \rightarrow 6 \cdot 9)\end{array}$ & $\begin{array}{c}0 \\
1 \cdot 1 \\
(0 \cdot 01 \rightarrow 6 \cdot 3)\end{array}$ \\
\hline
\end{tabular}

Table II Effect of added antibacterial agents upon 28 urinary isolates of Enterobacteriaceae in urine ${ }^{1}$

${ }^{1}$ For each observation the top figure shows the number of organisms giving a bactericidal response. The middle figure is the mean value of the ratio: $\frac{\text { viable count at time shown }}{\text { original viable count }}$. The lower bracketed figure is the observed range of these ratios.

occurred. Strains found to be sulphonamide resistant by the disk test failed to grow in urine containing sulphamethoxazole, and there was in fact no significant difference in the degree of inhibition of sulphonamide 'resistant' or 'sensitive' strains. Likewise there was no significant difference in the response of sulphonamide 'resistant' or 'sensitive' strains to either trimethoprim or co-trimoxazole (Student $t$ test of means).

\section{ANTIBACTERIAL PROPERTIES OF URINE FROM INDIVIDUALS RECEIVING THERAPEUTIC DOSES OF CO-TRIMOXAZOLE OR ITS COMPO- NENTS}

The finding that co-trimoxazole was not bactericidal in urine was confirmed when the same organisms were incubated in urine from either of two individuals who had received on separate occasions, sulphamethoxazole, trimethoprim, or the combina- tion (ratio $5: 1 \mathrm{w} / \mathrm{w}$ ) as co-trimoxazole (table III). Trimethoprim was significantly superior to co-trimoxazole at four $\mathrm{hr}(\mathrm{P}=0.003)$ but the agents were not significantly different at two $\mathrm{hr}(\mathrm{P}=0.75)$ or at six hr $(P=0 \cdot 60)$. Co-trimoxazole was significantly superior to sulphamethoxazole at all times. It was notable that sulphamethoxazole again antagonized the cidal effect of trimethoprim and that no significant correlation was found between apparent sensitivity to sulphonamides by the disk test and response to cotrimoxazole or its components in urine.

Co-trimoxazole or its individual components had a bacteriostatic effect in urine upon the single isolate of $E$. coli which appeared to be resistant to these agents by the antibiotic disk test. The clinical significance of this finding is difficult to assess.

Confirmation that the effect of co-trimoxazole was bacteriostatic was provided when similar results were obtained when a selection of 18 of the

\begin{tabular}{|c|c|c|c|}
\hline \multirow[t]{2}{*}{ Drug Regime } & \multicolumn{3}{|c|}{ Time of Incubation } \\
\hline & Two $\mathrm{Hr}$ & Four $\mathrm{Hr}$ & Six $\mathrm{Hr}$ \\
\hline Sulphamethoxazole $1 \mathrm{~g}$ twice daily & $\begin{array}{c}0 \\
1.9 \\
(0.6 \leftrightarrow 10)\end{array}$ & $\begin{array}{c}0 \\
12 \\
(0 \cdot 6 \rightarrow 88)\end{array}$ & $\begin{array}{c}0 \\
27 \\
(0 \cdot 3 \rightarrow 162)\end{array}$ \\
\hline Trimethoprim $160 \mathrm{mg}$ twice daily & $\begin{array}{c}0 \\
0.75 \\
(0 \cdot 1 \rightarrow 4 \cdot 6)\end{array}$ & $\begin{array}{c}6 \\
0.31 \\
(0 \cdot 01 \rightarrow 1 \cdot 3)\end{array}$ & $\begin{array}{c}9 \\
0.46 \\
(0.01 \rightarrow 4 \cdot 4)\end{array}$ \\
\hline $\begin{array}{l}\text { Co-trimoxazole (sulphamethoxazole } 0.8 \mathrm{~g} \text { with trimethoprim } 160 \mathrm{mg} \text {, } \\
\text { twice daily) }\end{array}$ & $\begin{array}{c}0 \\
0.69 \\
(0.3 \rightarrow 1 \cdot 3)\end{array}$ & $\begin{array}{c}0 \\
0 \cdot 60 \\
(0 \cdot 1 \rightarrow 1 \cdot 7)\end{array}$ & $\begin{array}{c}0 \\
0.55 \\
(0 \cdot 1 \rightarrow 1 \cdot 1)\end{array}$ \\
\hline
\end{tabular}

Table III Effect of urine from individuals receiving various antibacterial agents upon 28 urinary isolates of Enterobacteriaceae ${ }^{1}$

See footnote to table II. 
test organisms was incubated with urine from a third individual who had received therapeutic doses of this agent.

\section{Discussion}

Although the study of organisms in urine described here may not relate necessarily to the natural environment, since no attempt was made to study these agents at concentrations found in kidney tissue, it was probably closer to the conditions found in urinary infections than experiments performed in nutrient broth. The main conclusion was that co-trimoxazole or its components do not produce a reliable destruction of bacteria in urine and that trimethoprim alone would appear to be as effective, and possibly more so, than the mixture. It is puzzling that trimethoprim has not been subjected to a more extensive clinical evaluation in its own right.

Failure to show any difference between the response of sulphonamide-sensitive or -resistant organisms to co-trimoxazole in urine is supported by parallel findings in a clinical study of urinary tract infections (Acar, Goldstein, and Chabbert, 1973).

Variations in the response of organisms to these various antibacterials after different periods of incubation suggest that bacterial response may be a function of the stage of growth.

The clinical significance of laboratory tests for sensitivity to these agents remains in doubt and one cannot at present improve on the observation that therapeutic results with co-trimoxazole in urinary tract infections may be largely predicted from a knowledge of sensitivity tests in vitro to trimethoprim alone (Reeves, Faiers, Pursell, and Brumfitt, 1969).

The use of trimethoprim instead of co-trimoxazole is known to cause fewer side effects (Brumfitt and Pursell, 1972). The possible increased chance of selecting antibiotic resistant populations by a single agent may now be largely discounted in clinical practice (Lacey et al, 1973; Lewis et al, 1974), although the use of the combination for this reason did seem to be quite reasonable at the time when cotrimoxazole was introduced. The components of co-trimoxazole are incompatible in parenteral preparations. If our observations are found to apply in clinical practice, trimethoprim alone may well prove to be a useful drug for parenteral use. Whilst we agree with Brumfitt and Percival that it would be unwise at present to recommend the substitution of trimethoprim for co-trimoxazole there is obviously an urgent need for further clinical comparisons of these two agents in order to identify conditions for which the trimethoprim component should be given alone.

We are most grateful to Professor W. A. Gillespie for his interest and to Mr R. D. Jennings of Bristol Royal Infirmary for statistical help, and to Roche Products for a gift of trimethoprim tablets. This work was supported by grants from the Medical Research Committee of the United Bristol Hospitals to M.E.S. and E.L.L.

\section{References}

Acar, J. F., Goldstein, F., and Chabbert, Y. A. (1973). Synergistic activity of trimethoprim-sulphamethoxazole on Gram-negative bacilli: observations in vitro and in vivo. J. infect. Dis., 128, Suppl., S470-S477.

Brumfitt, W., and Pursell, R. (1972). Double blind trial to compare ampicillin, cephalexin, co-trimoxazole, and trimethoprim in treatment of urinary infection. Brit. med. J., 2, 673-676.

Cowan, S. T., and Steele, K. J. (1965). Manual for the Identification of Medical Bacteria. Cambridge University Press, London.

Gleckman, R. A. (1973). A cooperative controlled study of the use of trimethoprim-sulphamethoxazole in chronic urinary tract infections. J. infect. Dis., 128, Suppl., S647-S651.

Hoigné, R., Müller, U., and Schneider, H. R. (1969). Bactrim Roche, ein Kombinationspräparat von Sulfamethoxazol und Trimethoprim. Schweiz. med. Wschr., 99, 1511-1518.

Küchler, R., and Koch, U. J. (1973). The in vitro demonstration of the efficacy of trimethoprim as an antibacterial agent in a comparative bacteriological study on the effects of trimethoprim, sulphamethoxazole, and the combination trimethoprim/sulphamethoxazole. Chemotherapy, 18, 242-252.

Lacey, R. W., Anderson, J. D., Lewis, E. L., and Gillespie, W. A. (1973). Comparative efficacy of sulphonamide and co-trimoxazole. Lancet, 2, 509.

Lewis, E., Anderson, J. D., and Lacey, R. W. (1974). A reappraisal of the antibacterial action of co-trimoxazole in vitro. J. clin. Path., 27, 87-91.

Miles, A. A., Misra, S. S., and Irwing, J. O. (1938). The estimation of the bactericidal power of the blood. J. Hyg. (Lond.), 38, 732-749.

Reeves, D. S., Faiers, M. C., Pursell, R. E., and Brumfitt, W. (1969). Trimethoprim-sulphamethoxazole: comparative study in urinary infection in hospital. Brit. med. J., 1, 541-544. 
Ingram, G. I. C., Knights, S. F., Arocha-Pinango, C. L., Shepperd, J. P., and Pérez-Requejo, J. L. (1975). Simple screening tests for the diagnosis of isolated clotting factor defects. J. clin. Path., 28, 524-530.

Waaler, B. A. (1959). Contact activation in the intrinsic blood clotting system. Scand. J. clin. Lab. Invest., 11, Suppl. 37, pp. 53-57.

Wilson, W. J., Ingram, G. I. C., and Hills, M. (1971).

The use of kaolin or contact product in the one-stage assay of factor VIII. Coagulation, 4, 113-117.

\section{Letters to the Editor}

\section{Liver-cell Mass and Nuclear-cytoplasmic Ratio in Human Liver}

In spite of current interest in histoquantitation, reflected in your issue of February 1975 , there is as yet little information on measurement of tissue components of mammalian liver under the microscope, and figures cited vary widely. Thus, for instance, hepatocyte cytoplasm is said to account for $77 \%$ of liver volume in the rat (Weibel et al, 1969) while in man about $60 \%$ of the liver is said to be composed of liver cells (Sherlock, 1968).

We have recently calculated figures for formalin-tixed, paraffin-embedded liver biopsies on the basis of point-count morphometry. The work formed part of a thesis presented by one of us (LCCG) for the degree of $\mathrm{PhD}$ in the University of London. Liver cells in 20 normal human livers accounted for $80.5 \pm 4.2 \%$ of total volume (mean $\pm \mathrm{SD}$ ). Liver-cell cytoplasm alone accounted for $70.9 \pm 4.5 \%$ and nuclei for $9.6 \pm 1.9 \%$. The latter figures give a mean nuclear-cytoplasmic ratio of approximately 0.14 or $1: 7$. Our results suggest that liver cells form an even larger proportion of human liver than was previously supposed.

$$
\begin{array}{r}
\text { LUIZ CARLOS C. GAYOTTO } \\
\text { PETER J. SCHEUER } \\
\text { Department of Histopathology, } \\
\text { Royal Free Hospital, } \\
\text { Pond Street, } \\
\text { London NW3 } 2 Q G
\end{array}
$$

\section{References}

Sherlock, S. (1968). Diseases of the Liver and Biliary System, 4th ed., p. 10. Blackwell, Oxford.

Weibel, E. R., Stäubli, W., Gnägi, E. R., and Hess, F. A. (1969). Correlated morphometric and biochemical studies on the liver cell. I Morphometric model, stereologic methods, and normal morphometric data for rat liver. J. cell. Biol., 42, 68-91.

\section{Correction to Error}

Anderson, J. D., Lacey, R. W., Lewis, E. L., and Sellin, M. A. (1974). Failure to demonstrate an advantage in combining sulphamethoxazole with trimethoprim. J. clin. Path., 27, 619-22.

The above paper contains two transscription errors, one of which appears to invalidate the conclusions in the text. Table II, column 3, line 4 (sulphamethoxazole in urine): for 0 read 1; Table II, column 3 , line 12 : for $(0.01 \rightarrow 6.3)$ $\operatorname{read}(0.11 \rightarrow 6.3)$.

J. D. ANDERSON
Department of Microbiology,
District Laboratory,
County Hospital,
Monkgate,
York YO3 $7 P G$.

\section{Book reviews}

The Acid-Base Status of the Blood. 4th Edition. By Ole Siggaard-Andersen. (Pp. xii +229 ; illustrated; Dan. Kr. 110:00.) Copenhagen: Munksgaard. 1974.

This book is something of a tour-de-force. It will be of the greatest scientific value to those trying to master the complexity of all the known factors concerned in acid-base blood chemistry. The author stresses mathematical and chemical exactness and this makes for very heavy going on the part of all who cannot describe themselves as physical chemists.

Nevertheless, this book should be a valuable comprehensive addition to the library of a clinical chemist. The sections on analytical methods are quite superb, and the sources of error are clearly outlined. The bibliography is excellent.

A. GUZ

Atlas of Human Glomerular Pathology. By Peter M. Burkholder. (Pp. 44; 100 figures; $\$ 35.00$.) New York and London: Harper and Row. 1974.

In recent years advances in both experimental and human renal pathology have been rapid. Renal biopsy techniques have been improved and it is now mandatory in most centres for histological examination of kidney tissue to include immunofluorescence and electron microscopy as well as conventional light microscopy. The appearance of this atlas is thus timely and, coming from one who has himself contributed much to our present understanding of renal disease, it is authoritative as well. A chapter is devoted to each of the main glomerulopathies, and the illustrations of the light microscopic, immunofluorescent, and ultrastructural findings are clear and informative. Each chapter begins with a 